EPiC Series in Engineering
Volume 3, 2018, Pages 470-475
HIC 2018. 13th International
Conference on Hydroinformatics

\title{
Managing large geodatasets for urban flood risk mapping: The Mexican flood risk atlas
}

\author{
Laurent G. Courty ${ }^{1}$, J. Agustín Breña-Naranjo ${ }^{1}$, and Adrián Pedrozo-Acuña ${ }^{1}$ \\ Instituto de Ingeniería, Universidad Nacional Autónoma de México, Circuito Escolar, Ciudad \\ Universitaria, Coyoacán 04510, Ciudad de México, Mexico
}

\begin{abstract}
We present a flood risk mapping framework created in the context of the update of the Mexican flood risk atlas. This framework is based on a nation-wide GIS database of map time-series. Those maps are used as forcing for a deterministic, raster-based numerical model. For each catchment of interest, the model retrieves the data from the GIS and perform the computation on the specified area. The results are written directly in the GIS database, which facilitate their post-processing. This methodology allows 1) the generation of flood risk maps in cities located across the national territory, without too much effort in the pre and post-processing of information and 2) a very efficient process to create new flood maps for urban areas that have not been included in the original batch.
\end{abstract}

\section{Introduction}

Mexico is highly vulnerable to extreme rain events due to its geographical location. For instance, the incidence of cyclonic precipitation can bring significant flooding [1]. Facing this reality, the Mexican authorities started a plan to update the country's flood risk maps. As part of this initiative, the Engineering Institute of the National Autonomous University of Mexico (UNAM) was tasked by the National Water Commission (CONAGUA) to define the flood risk maps of 23 urban areas, throughout the Mexican territory (see Figure 1). Within this context, urban flood risk maps are generated using a deterministic model approach and for 6 return periods. Although the urban areas comprised in this study are located throughout the country, most of the input data are coming from similar sources. Traditionally, the input data in flood modelling are prepared for each study site, resulting in a time consuming task for the modeller. In order to reduce the amount of work required to prepare the input data, we decided to take a more efficient approach by preparing the data nationwide and then running the model on specific simulation domains. In this paper, we will present this framework aimed at preparing and managing a national database of input data (elevation, friction, soil data, precipitation etc.) and how the simulation is carried-out using a GIS integrated model. 


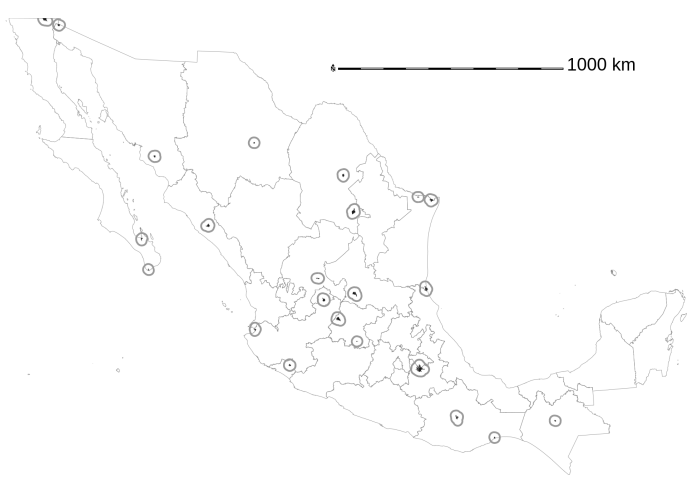

Figure 1: Location of the study areas in Mexico.

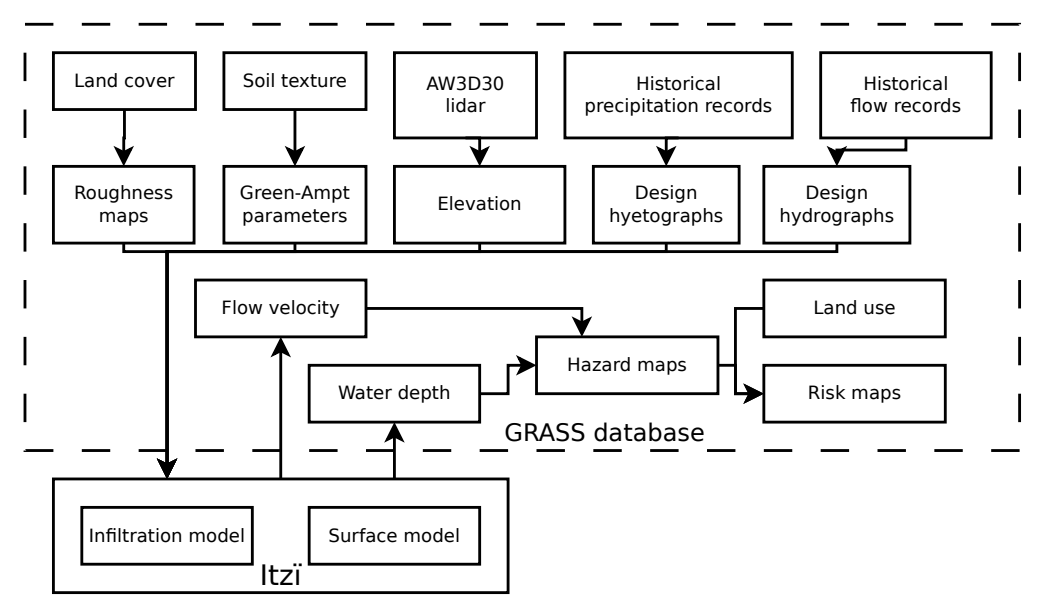

Figure 2: Diagram of the proposed methodology.

\section{Methodology}

The basic concept of the presented methodology is to create a nation-wide GIS database of input data and then localise the flood simulations without further processing of the data. This framework is based on open-source software, namely the GIS and the flood model. The diagram shows in Figure 2 presents the type of entry data being used, and the corresponding workflow.

\subsection{GIS environment}

We use GRASS, an open source GIS that easily handles large datasets [2]. More importantly for this study, GRASS allows the definition of a "computational region", that is a geographical subset inside the full domain where all raster analysis are carried out. The GRASS computational region also defines the resolution at which the operations are realised. This concept permits the use of large datasets of heterogeneous resolution without the need to crop or resample the original data. Furthermore, GRASS includes a temporal GIS that allows creating and handling map time-series, including precipitation [3]. 


\subsection{Hydrodynamic model}

The selected numerical tool for this investigation corresponds to Itzï, a raster-based flood computer model that is build upon GRASS GIS. Itzï has been described in detail in a previously published open-access article [4]. Therefore, we will inhere confine ourselves to a short description of the model. Itzï implements both a partial-inertia numerical scheme [5] when the water level is above a given threshold, and a simplified rain-routing technique for direct rainfall [6] otherwise. It uses the Green-Ampt formula to estimate the losses due to infiltration. Itzi retrieves the geographical information it needs through the GRASS GIS Application Programming Interface (API), which in turn performs on-the-fly raster resampling. The results are exported to the GRASS database as raster time-series.

\section{Application}

We applied this methodology for the creation of hazard and risk maps in 23 cities across Mexico. In this section we will present how we generated the input data and an example of the obtained results.

\subsection{Input Data}

The main input data that we are using for flood modelling are the Digital Elevation Model (DEM), the Manning's n, the Green-Ampt parameters and finally the rainfall data. The first three are represented as raster maps, while the precipitation is in the form of raster time-series to account for the evolution in time of the rainfall. All those maps have been created on the national scale, including some parts of the USA for cross-border catchments.

The DEM come from two sources. As a first option, we use Digital Terrain Model (DTM) from the Mexican National Institute for Statistics and Geographical Information (INEGI). Those DTM are created from aerial lidar survey and have an horizontal resolution of $5 \mathrm{~m}$. Unfortunately, those data are note covering the entire Mexican territory. When not available, we used the ALOS World 3D $30 \mathrm{~m}$ (AW3D30), a Digital Surface Model (DSM) distributed by the Japan Aerospace eXploration Agency (JAXA) [7]. Figure 3 shows the AW3D30 coverage of Mexico. We selected this near-global DSM after a comparison against the more commonly used SRTM and ASTER [8]. The hydraulic conditioning has been carried out in two steps. First, the no-data areas of the DEM have been filled-up. Second, we carved in the DEM the main streams with the help satellite imagery.

The parameters for the Green-Ampt infiltration formula are estimated using soil data. For this, we employ the global soil database SoilGrids $1 \mathrm{~km}$ [9]. The sand and clay content values are used to classify the soil into texture classes. Then, we use experimental values to estimate the conductivity, capillary pressure and effective porosity of each soil class [10].

We created the map of Manning's n based on the Global Land Cover $30 \mathrm{~m}$ (GLC30), distributed by the National Geomatics Center of China [11]. We then used typical $n$ values for a given land use to obtain the final roughness map through classification [12].

The rainfall time-series were created by using the results of a statistical analysis of the historical records of 2293 rain gauges located all over Mexico [13]. The Figure 4 shows the density of the rain gauges that have been used for this study. We created a design hyetograph for each rain gauge and each return period of 2, 5, 10, 20, 50 and 100 years, respectively. Then we created a raster map for each time step using IDW interpolation at a resolution of $300 \mathrm{~m}$. Those maps are then organised within a GRASS raster time-series for each return period with 


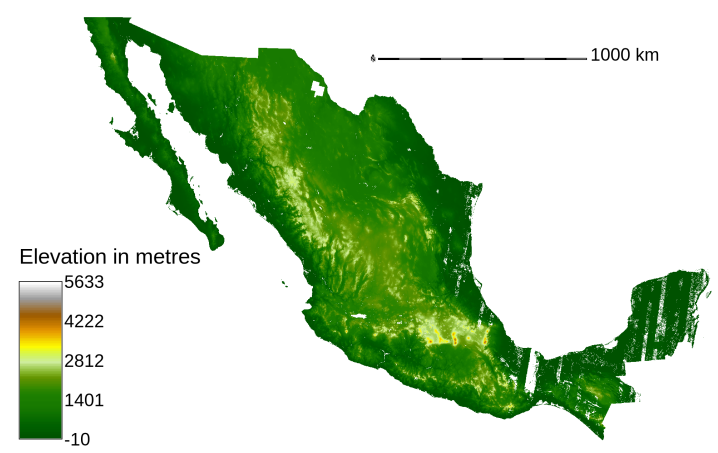

Figure 3: Digital Elevation Model of the Mexican territory from the AW3D30. Horizontal resolution of $30 \mathrm{~m}$, representing more than 7 billion raster cells.

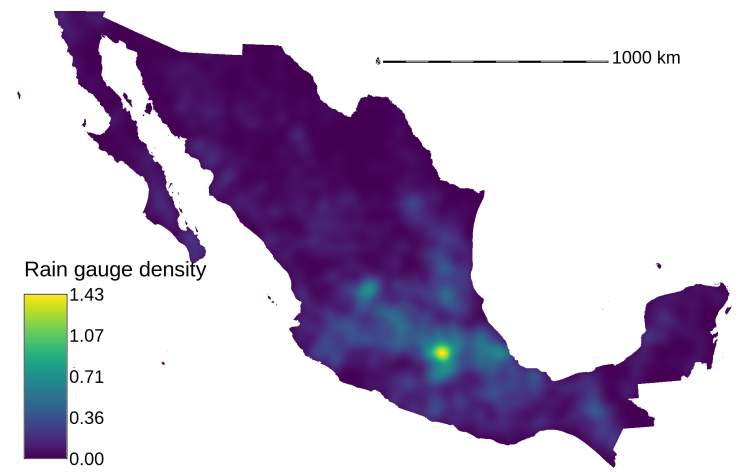

Figure 4: Density of rain gauges over the Mexican territory. Map obtained with a $100 \mathrm{~km}$ Gaussian kernel.

a time step of 1 hour. Figure 5 shows an example of a map of the maximum rainfall intensity for a 100 year return period.

The size of the studied catchments varies from $118 \mathrm{~km}^{2}$ to $13437 \mathrm{~km}^{2}$. In order to limit the computational time, the catchments over $800 \mathrm{~km}^{2}$ were modelled at $30 \mathrm{~m}$ of horizontal resolution. Those using entirely the lidar DTM and below $800 \mathrm{~km}^{2}$ have been modelled at $15 \mathrm{~m}$.

Additionally, The Mexican authorities maintain a network of hydrometric stations. When sufficient records where available, we employed the historic data of those stations to create a design hydrograph of each return period for the corresponding station. These hyetograph are then used as an input to the model, permitting the reduction of the total computational domain.

\subsection{Example of results}

In this study, the numerical model was set to export the maximum water depths (see an example in Figure 6) and maximum flow velocities. Those two maps are in turn combined into hazard maps. Furthermore, flood risk maps were created as the combination of hazard maps and land use maps, displaying higher risk in populated areas. 


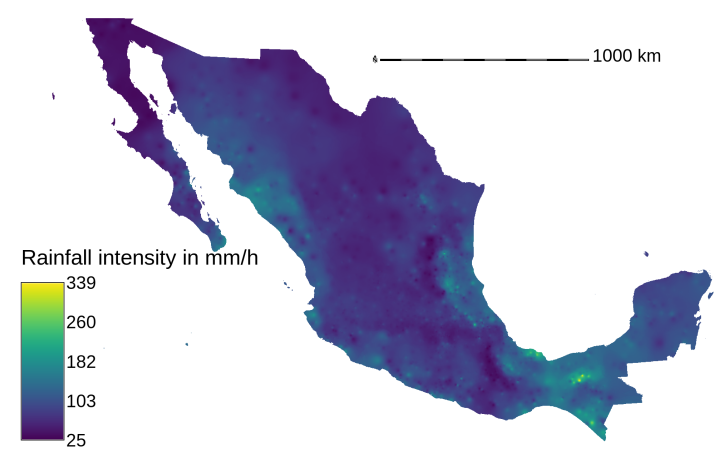

Figure 5: Maximum rainfall intensity for a 100 year return period. This rainfall has a duration of 24 hours and a time-step of 1 hour. The map is created by an IDW interpolation of 2293 rain gauges at an horizontal resolution of $300 \mathrm{~m}$.

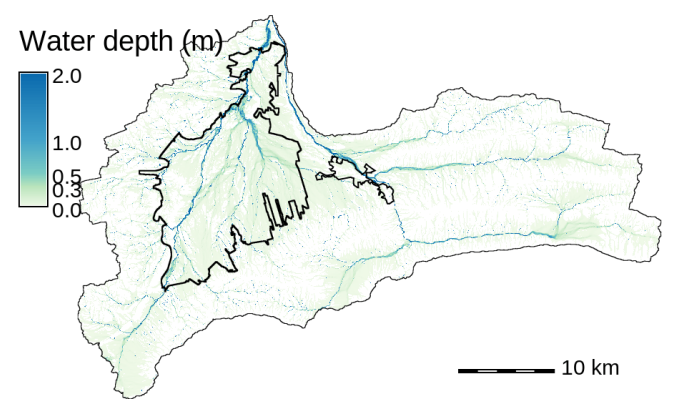

Figure 6: Maxima water depths in the catchment of Saltillo, Coahuila. The black lines delimit the urban areas.

\section{Conclusion}

We presented a framework for geodata management in Mexico that combines remote sensing data, modern GIS techniques and a fast 2D hydrodynamic model. The efficient handling of a large database at heterogeneous horizontal resolutions allowed a fast generation of flood risk maps in 23 urban areas in Mexico. Being able to maintain the data at their original resolution by the use of on-the-fly resampling reduces the size of the database, which is appreciable when dealing with large datasets. This methodology proved its potential for its use at a much larger scale (possibly global) and for on-demand flood mapping. Indeed, once the input database is created, running the simulation in a new catchment requires reduced work from the modeller.

\section{References}

[1] A. Pedrozo-Acuña, J. A. Breña-Naranjo \& R. Domínguez-Mora, 2014 The hydrological setting of the 2013 floods in Mexico. Weather vol. 69, no. 11 295-302

[2] M. Neteler, M. H. Bowman, M. Landa \& M. Metz, 2012 GRASS GIS: A multi-purpose open source GIS. Environ. Model. Softw. vol. 31 124-130. 
[3] S. Gebbert \& E. J. Pebesma, 2014 TGRASS: A temporal GIS for field based environmental modeling. Environ. Model. Softw. vol. 53 1-12.

[4] L. G. Courty, A. Pedrozo-Acuña \& P. D. Bates, 2017 Itzï (version 17.1): an open-source, distributed GIS model for dynamic flood simulation. Geosci. Model Dev. vol. 10, no. 4 1835-1847.

[5] G. A. M. de Almeida \& P. D. Bates. 2013 Applicability of the local inertial approximation of the shallow water equations to flood modeling. Water Resour. Res. vol. 49, no. 8 4833-4844.

[6] C. C. Sampson, P. D. Bates, J. C. Neal \& M. S. Horritt, 2013 An automated routing methodology to enable direct rainfall in high resolution shallow water models. Hydrol. Process. vol. 27, no. 3 $467-476$.

[7] T. Tadono et al., 2016 Generatiojn of the 30 m-mesh global digital surface model by ALOS PRISM. ISPRS - Int. Arch. Photogramm. Remote Sens. Spat. Inf. Sci. vol. XLI-B4 157-162.

[8] L. G. Courty, J. C. Soriano-Monzalvo, \& A. Pedrozo-Acuña, 2017 Evaluation of open-access global digital elevation models (AW3D30, SRTM and ASTER) for flood modelling purposes.

[9] T. Hengl et al., 2014 SoilGrids $1 \mathrm{~km}$-global soil information based on automated mapping. PLoS One vol. 9, no. 8 p. e105992.

[10] W. J. Rawls, D. L. Brakensiek, and N. Miller, 1983 Green-Ampt infiltration parameters from soils data. J. Hydraul. Eng. vol. 109, no. 1 62-70.

[11] J. Chen et al., 2014 Global land cover mapping at $30 \mathrm{~m}$ resolution: A POK-based operational approach. ISPRS J. Photogramm. Remote Sens. vol. 103 7-27.

[12] V. Te Chow, 1959 Open channel hydraulics. McGraw-Hill Book Company, Inc.

[13] R. Domínguez, E. Carrizosa, G. E. Fuentes, M. L. Arganis, J. Osnaya \& A. E. Galván-Torres, 2018 Análisis regional para estimar precipitaciones de diseño en la república mexicana. Tecnol. y Ciencias del Agua vol. 9, no. 1 05-29. 